\title{
Nuevas perspectivas para un viejo problema: la edición crítica del romancero de fuente tradicional
}

\author{
Sandra BоTO \\ CIAC/CEAO, Universidade do Algarve \\ sandra.boto@gmail.com
}

\section{RESUMEN}

Este estudio presenta, de forma muy sintética, las bases para una edición crítica del Romanceiro del escritor romántico portugués Almeida Garrett.

Se fundamenta, en este trabajo, la perspectiva ecdótica escogida de cara a preparar dicha edición, teniendo en cuenta la naturaleza de los materiales garrettianos acopiados hasta el día de la fecha, y actualizados en la recensio.

Se problematiza la naturaleza de los materiales reseñados, teniendo en cuenta las características de los romances de Almeida Garrett recogidos en la tradición oral, parte importante de los romances pertenecientes a la colección de este poeta y por él reelaborados según los gustos románticos de la época. Sin embargo, la aplicación de la crítica textual a la edición de estos textos tiene características muy específicas que aquí se plantearán y discutirán. Si, por un lado, se desea ofrecer una buena edición, conjeturándose lo que habrá sido la última voluntad del autor y la finalidad de su Romanceiro, por otro, para cada tema, siguiendo métodos de la ecdótica, se establecerá un arquetipo de la versión tradicional que el poeta conoció y a partir de cuyos versos edificó cada romance que edita y modifica, con mayor o menor parsimonia. Para ejemplificar la metodología utilizada, se presenta, en este estudio, el romance "Gaiferos".

Palabras clave: Ecdótica; Romancero; Almeida Garrettt; Edición crítica

\begin{abstract}
This essay offers a synthetic presentation of the foundations for a critical edition of the $R o-$ manceiro by the Portuguese Romantic writer Almeida Garrett.

This work will be based on textual criticism, a view which will be followed to carry out this edition, which will be related with the nature of Garrett's materials which we now possess, after the updating of their recensio.

We shall put into question the nature of the materials under scrutiny, connecting them with the characteristics of Garrett's "romances" of traditional origin, related to a substantial part of the "romances" which the poet owned and re-elaborated in accordance with the then current Romantic taste. Therefore, the application of a methodology of textual criticism to


the edition of these texts will acquire very specific outlines which will be here discussed. If on the one hand one should offer a reliable edition of the texts, following what can be assumed as the latest wish of the poet and the purposes of his Romanceiro as an opus, one can just as well - through ecdotical procedures which will be here outlined - propose for each theme, an archetype of the traditional version which the poet would have come across and from whose lines he would have constructed each text which he would edit and transfigure, some more, others less (according to his personal taste). To illustrate this method, we shall give the example of the Garrettian "romance" Gaifeiros.

Keywords: Ecdotics; Traditional "Romanceiro"; Almeida Garrett; critical edition.

Sumario: 1. Los documentos del Romanceiro y la necesidad de editarlos 2. Pautas para la edición crítica 3. El ejemplo editorial del romance de Gaiferos

João Baptista da Silva Leitão de Almeida Garrett (1799-1854) ha sido el gran representante de la escuela romántica en Portugal. Activo político liberal, obligado a un exilio británico, después del triunfo de los absolutistas lusos, en 1823, forjará su pensamiento estético mediante la lectura de autores como Scott, Byron, Burger, entre otros ${ }^{1}$.

Sobre Garrett y su programa romántico cabrá agregar -elemento que juzgo de interés para el tema que aquí pretendo desarrollar- que fue este autor el introductor, en Portugal, y en la Península Ibérica, del interés por el Romancero de la tradición oral moderna ${ }^{2}$. Sin embargo, no han sido propósitos filológicos, ni siquiera etnográficos, los que impulsaron este autor hacia este género. Según sus propias afirmaciones, confirmadas por el estudio de los textos que dedica al Romancero, su motivación radica en las nuevas formas de expresión poética, configuradas por el paradigma estético romántico, que intenta propagar en Portugal: una poesía que, bajo su perspectiva estética (romántica, recordémoslo), fuera sinónimo de poesía nacional. "Nenhuma coisa pode ser nacional se não é popular", escribirá en $1843^{3}$.

${ }^{1}$ Sobre la biografía de Almeida Garrett y las relaciones de su obra con los hechos biográficos y las circunstancias políticas y artísticas de su época, señalo, entre otras, tres obras fundamentales: G. Amorim (1881 y 1884); T. Braga (1903) y O. Monteiro (1971).

${ }^{2}$ Aunque se siga señalando tradicionalmente 1825 como el año (encuesta en la Cárcel de los Señores de Sevilla) en que por primera vez se coleccionan romances de la tradición oral moderna, ya en 1824 (esta fecha se puede leer claramente en la portada de su cuaderno autógrafo) Almeida Garrett anotaba sus primeras versiones portuguesas de origen tradicional. Cabe aún subrayar que en dicho cuaderno y en esa fecha, Garrett acopia sus versiones con la más perfecta conciencia del papel que el romancero tradicional tendrá en su plan de creación del Romanticismo en Portugal.

${ }^{3}$ A. Garrett (1843), pp XXII. 


\section{Los documentos del Romanceiro y la necesidad de editarlos}

Después de estas palabras prologales, hagamos una breve recensio del romancero de Garrett ${ }^{4}$, justificando, a la vez, la necesidad de una edición crítica de sus textos. El corpus romancístico garrettiano se puede dividir en dos grandes grupos: a) el publicado por él, en especial, los romances editados en 1828 y las colecciones romancísticas impresas entre 1843 y 1851 y b) el corpus manuscrito, atesorado, hasta hace poco tiempo, en dos colecciones.

Así pues, de su bibliografía sobre la balada peninsular, conservamos los siguientes títulos:

- de 1828, Adozinda;

- de 1843, el Romanceiro e Cancioneiro Geral, I, que reedita Adozinda; (este tomo fue, de nuevo, publicado, con añadidos, en vida de Garrett, en 1853). Constan en esta obra, principalmente, baladas de 'propia invención', teniendo, algunas, fuentes tradicionales;

- de 1851 (Romanceiro, II y III), tomos integralmente dedicados a coleccionar versiones más o menos cercanas a la tradición oral. Algunas de ellas, fijadas en el tomo III, son romances de fuente autoral, sin relación con textos conservados oralmente.

En lo que concierne a los textos manuscritos, se tenía conocimiento de la colección de la Biblioteca Geral de la Universidad de Coimbra (docs. 59 a 63) y del "Cancioneiro de romances, xacaras, soláos (...)", cuaderno manuscrito autógrafo de Garrett, depositado en la Biblioteca de la Faculdade de Letras de dicha universidad portuguesa. Aunque de forma parcial, los materiales contenidos en estos acervos fueron objeto de una edición llevada a cabo por la familia Costa Dias (Augusto y Luís), en 1983 y 1988, caracterizada, sin embargo, por graves deficiencias ecdóticas.

Los materiales existentes eran ya, sin duda, suficientes para justificar una edición crítica de los tres tomos del Romanceiro, impresos por Garrett, basándonos, solamente, en los testimonios manuscritos, hasta hace poco conocidos, constituidos por versiones o fragmentos de versiones que, en parte, sirvieron de material primigenio para los romances por él publicados.

Pere Ferré, ante la existencia de estos materiales, señaló en varios de sus estudios la imperiosa necesidad de preparar una edición crítica del Romanceiro de Almeida Garrett, especialmente debido al método editorial del romántico portugués, muy común, recordémoslo, en su época. En realidad, los treinta y seis temas romancísticos de fuente tradicional (este era su número hasta el año 2004) de su corpus impreso y manuscrito, presentan una reelaboración estética de valor muy desigual,

\footnotetext{
${ }^{4}$ No mencionamos aquí algunas de las versiones de Garrett conocidas gracias a la prensa o insertadas en sus obras literarias para no hacer muy larga esta lista. La recensio completa y comentada del romancero publicado e inédito de Garrett se puede consultar en mi tesis doctoral.
} 
siendo más exuberante, como es lógico, en los textos impresos y más parsimoniosa en sus manuscritos. A la vez, identificamos en los testimonios manuscritos una mayor proximidad a la tradición oral, hecho particularmente interesante para el estudio y mejor conocimiento del romancero editado en los primeros cincuenta años del siglo XIX.

En una comunicación hecha en Madrid, en la Universidad Complutense, en 2002, Ferré sintetizó el problema de la siguiente forma:

Para Garrett, editar un romance significaba ofrecer un texto expurgado de 'incorrecciones', 'lagunas' u otros defectos que a su juicio caracterizaban el estado corrupto del romancero oral y, por esta vía, gran parte de los textos depurados servirían para el renacimiento de una literatura nacional inspirada en la más primitiva literatura lusitana ${ }^{5}$.

Anclada en estos principios, la edición crítica que me propongo hacer tendrá en cuenta las características particulares del método editorial de Garrett que pugnaba por la presentación de versiones pulcras del punto de vista de la intriga y del discurso, hecho palpable, a menudo, en la elaboración de versiones facticias, en las que se cruzan la oralidad y la escritura -como era común entre los editores europeos de baladas en estos años-.

Traté de dejar claro, al empezar este estudio, que Garrett no tenía una concepción filológica de fidelidad al texto ni a su fuente. Le interesaba, solamente, el papel estético y fundador que los romances iban adquiriendo en su proyecto: provocar el renacimiento de la literatura nacional portuguesa. Cabe, a mi juicio, al editor crítico, darse cuenta de estas variables y conjugarlas en un método editorial coherente.

De hecho, el conocimiento que se tenía del Romanceiro garrettiano en el pasado siglo ya delimitaba claramente el problema y las líneas editoriales que deberían seguirse. Pere Ferré, empeñado en aproximarse, con la máxima cautela, a la delimitación de las lecciones tradicionales presentes en el romancero de Garrett ${ }^{6}$, proponía en 2003 la colación de todos los testimonios garrettianos (impresos y manuscritos) de cada romance con las respectivas versiones recogidas en la tradición moderna ${ }^{7}$.

Pero he aquí que, en 2004, ocurre un hecho que revoluciona el conocimiento de los estudios sobre el romancero de Garrett: aparecen más de cuatrocientas páginas manuscritas (casi todas autógrafos de Garrett), en el sótano de una vieja casa en el lisboeta Barrio Alto, dedicadas al romancero. Aquí entra, en la historia del roman-

\footnotetext{
${ }^{5}$ P. Ferré (2006), p. 88.

${ }^{6}$ Cf. P. Ferré (2003), pp. 142-151.

${ }^{7}$ Muy recientemente, en un estudio que acaba de publicarse, Ferré dedica una aguda reflexión al problema de la edición del romance tradicional, presentando fundamentos muy importantes para la edición crítica del romancero de Almeida Garrett, los que he seguido en mi trabajo. Véase P. Ferré (2011).
} 
cero, la 'Colección Futscher Pereira', compuesta por borradores de versiones (muchas inéditas) e introducciones a los temas ya publicados, especialmente entre 1843 y 1851. Estos papeles pertenecieron, seguramente, al Consejero Deslandes, erudito bibliófilo, descendiente de viejos impresores franceses, residentes en Portugal desde el siglo XVII, y administrador de la "Imprensa Nacional" en los últimos años del siglo XIX y comienzos del pasado siglo.

El inventario de este acervo, que con detalle estudié en mi tesis doctoral, agrega cincuenta nuevos temas inéditos (de fuente tradicional y no tradicional, fechados probablemente entre 1840 y 1853) a los romances ya conocidos. Mientras tanto, algunas de estas versiones fueron divulgadas por la propietaria de la colección, la dra. Vera Futscher Pereira ${ }^{8}$.

\section{Pautas para la edición crítica}

Del análisis del corpus de romances inéditos de esta colección y de la lectura de los documentos no poéticos presentaré, de forma sintética, las conclusiones más importantes que he sacado para la edición crítica del Romanceiro:

1) el plan definitivo de la edición del Romanceiro en cinco Libros figura en la introducción al tomo II publicado en 1851. Este plan se encuentra claramente influenciado por la organización temática del Romancero general de Agustín Durán. Se desconocían los planes de Garrett para continuar su obra ya que publicará este autor solamente dos de los cinco libros prometidos. Estos manuscritos nos dan informaciones cabales sobre la preparación de los futuros libros (basados en los mencionados textos inéditos). Tenemos, pues, la última voluntad editorial de Garrett y lo que conjeturamos como la última redacción de los romances inéditos. Desde ahora, figuran materiales inéditos que complementan al Romanceiro conocido y, además, un conjunto de precisiones de la pluma de Garrett, que permitirán al editor crítico concluir de forma segura su tarea.

2) En síntesis, se afirmará que la Colección Futscher Pereira permitió recuperar muchos de los manuscritos que sirvieron de base a la impresión de versiones de romances publicados en 1828, 1843 y 1851, con informaciones destinadas a la imprenta y, en muchos casos, ofrece redacciones anteriores ${ }^{9}$.

\footnotetext{
${ }^{8}$ Asimismo, se inventariaron también documentos de otro tipo, especialmente tres conjuntos de textos de gran interés para la comprensión del pensamiento de Garrett sobre la poesía tradicional: planes editoriales, listas bibliográficas y apuntes. Sin duda que la contribución de estos documentos a fin de enmarcar el Romanceiro de Garrett como obra de un autor y reflejo de un pensamiento es importantísima. También lo es para la edición de su obra ya que revelan el laboratorio conceptual de su creación romanceril y, a la vez, le otorgan la lógica de que carecía. Véase el inventario de la Colección Futscher Pereira en S. Boto (2011), pp. 143-154.

${ }^{9}$ Véase el inventario de la colección (ibid.).
} 
3) Con la Colección Futscher Pereira aumentó significativamente el número de temas romancísticos de Garrett: 54 romances de fuente tradicional y 45 poemas cuya fuente no es un romance tradicional (de estos, 30 son exclusivamente librescos y una parte de ellos de autor conocido). Así pues, de acuerdo con estos resultados, la consecuencia más obvia será que, desde el punto de vista de la determinación de las fuentes (paso fundamental para entender el trabajo de la creación romántica en este tipo de poemas), casi la mitad de los textos no tienen origen tradicional. Se verifica que la poesía popular, tal como la entendía Almeida Garrett, iba mucho más allá de la tradición oral. Y esta lectura desautoriza el que una edición crítica del Romanceiro de Garrett expurgue, sin problemas de conciencia, este grupo de poemas no tradicionales, por respeto filológico a la obra.

Teniendo en cuenta estas reflexiones, propongo que abandonemos, por ahora, el tratamiento editorial de los romances de fuente no tradicional ya que los problemas de fijación presentados por estos textos son mucho menores y, principalmente, distintos, de los que plantean los textos de fuente romancística tradicional ${ }^{10}$.

En el caso de los romances de fuente poética tradicional la elaboración garrettiana es más compleja presentando casos de a) composición de versiones facticias, o de b) creación de textos mediante la incorporación, en versiones de origen tradicional, de fragmentos poéticos no orales, a fin de rellenar lagunas narrativas o de presentar retoques que garanticen verosimilitud o colorido medieval. Una vez más, Garrett actuó principalmente como poeta.

Pero ¿será deseable proponer que se intenten restaurar, solamente, las versiones tradicionales que sirvieron de fuente al texto de Garrett ignorando un Autor cuya obra y proyecto editorial son, desde la aparición de los manuscritos de la Colección Futscher Pereira, mucho mejor conocidos?

He aquí dos objetivos distintos: uno de ellos intentará recuperar lo que quedó hacia atrás, o sea, las fuentes orales perdidas; el otro, utilizando la Crítica Textual, se propone fijar una obra de acuerdo con lo que se entiende ser la última voluntad del autor. Así, el trabajo que me propongo llevar a cabo, teniendo en cuenta las particularidades de este Romanceiro, se dividirá en dos tomos independientes:

1) en el primero se editará críticamente la última voluntad autoral conjeturada o expresada (de los textos de fuente tradicional $-\mathrm{y}$ de los de fuente no tradicional, aunque no los discutamos en este texto-, reuniendo versiones editadas o inéditas) cotejando todos los testimonios a fin de corregir errores y presentando un aparato genético que permita mostrar el proceso creativo de Garrett;

2) el segundo está dedicado a restaurar los arquetipos de los romances de fuente tradicional, editados e inéditos, mediante la colación con los hemistiquios de todas las versiones recogidas en la tradición oral de cada tema, que refrendarán o no las

${ }^{10}$ Sobre los criterios de edición crítica de los romances no tradicionales de Garrett, véase S. Boto (2011), 524-575. 
lecciones presentadas por Garrett, expurgando a la vez las intervenciones hechas por el autor en el texto (collatio y selectio de variantes). Se pasará, finalmente, a la propuesta de la constitutio textus del arquetipo tradicional. En el caso de Garrett (y no solamente en este autor, es sabido) la búsqueda del original oral es tarea imposible. Es más, el estudio de los textos que por colación y selección señalamos como primeros revela que dichas versiones han sufrido ya intervenciones ajenas a la cadena tradicional, o sea, intervenciones de la minerva de Garrett. De este modo, el original no existe físicamente ni podrá ser recuperado por conjetura debido a la naturaleza misma de los textos tradicionales ya ampliamente estudiada por la escuela pidalina.

\section{El ejemplo editorial del romance de Gaiferos}

Permítanme, no obstante, que ilustre el modus operandi del trabajo de edición que acabo de enunciar con la presentación de un ejemplo, el del romance de Dom Gaifeiros $^{11}$. Este texto, cuyas distintas fuentes identificadas presentan una compleja relación entre sí, es uno de los más singulares casos de la manipulación garrettiana. Es un excelente ejemplo de una tradición mixta en la que lo oral y lo escrito se confunden. La reciente aparición del manuscrito de Gaiferos, localizado en la Colección Futscher Pereira, permitió que se introdujeran nuevas perspectivas a un estudio que, de otro modo, permanecería cerrado sobre sí mismo por falta de información. Por esta razón se utilizaron las bases teóricas de la edición crítico genética, tal como la definió Giuseppe Tavani ${ }^{12}$, que asume como punto de partida el texto que el autor consideró (o consideraría) definitivo y traza la cronología del mismo mediante el estudio de su génesis, o sea, de los aparatos genéticos.

Se creía que la versión de Gaiferos de Garrett había sido compuesta solamente a partir de la versión antigua fijada por Durán en el Romancero general de 1849-51, no teniendo ningún tipo de relación con la tradición oral, aunque Garrett hubiese afirmado que tenía "em minha mão cópias authenticas do cantar do povo [...] d'aquella provincia [Tras-os-Montes]" ${ }^{\prime 13}$ y se refiriera a una versión encontrada en la misteriosa colección manuscrita del siglo XVIII del Caballero de Oliveira, de cuya existencia mucho se ha dudado, aún después de la noticia publicada por Lindley Cintra $^{14}$ sobre su posible realidad. He aquí el modelo editorial, separándolo en dos tomos con distintos objetivos:

1) Tomo I: Fijación crítica, genética y anotada

\footnotetext{
${ }^{11}$ Publicado en A. Garrett II (1851), pp. 250-267.

${ }^{12}$ G. Tavani (1999), pp. 143-149.

${ }^{13}$ A. Garrett II (1851), pp. 244-245.

${ }^{14}$ Véase la cita bibliográfica completa de la noticia de Cintra al final en Obras Citadas.
} 
Por lo anteriormente expuesto, la edición de este texto deberá contemplar por un lado su fijación crítica, genética y anotada. Se edita la última versión (la publicada por Garrett en 1851) y se ofrecen, en aparato final, las variantes de las dos redacciones de los manuscritos Futscher Pereira (la única colección manuscrita que contiene testimonios de este romance).

Observemos la propuesta de edición. Como criterio editorial optamos por respetar integralmente la voluntad y los planteamientos de Garrett, manteniéndose la fijación en verso corto, la ortografía y la puntuación, interviniendo solamente en los casos en que los manuscritos y el usus scribendi del poeta nos sugieran que se trata de una lección dudosa (errores de imprenta, etc). La conservación de la ortografía original, con tal que no tenga consecuencias fonéticas, será considerada más o menos irrelevante de acuerdo con el tipo de edición, más académica o de divulgación. En cualquier caso, se optará siempre por no integrar en el texto informaciones de ámbito genético de modo que no dificulten la lectura, relegando estos datos para el aparato. La fijación del romance estará siempre acompañada, a pie de página, por notas explicativas y por la indicación, debidamente justificada, de todas las intervenciones efectuadas en el poema que se edita. Al final de Dom Gaifeiros se establecerán las notas de Garrett al texto. Dichas notas se señalan a lo largo del poema con numeración entre paréntesis, a fin de evitar que las notas del editor crítico se confundan con las de Garrett.

En el aparato genético se optará por un conjunto de símbolos muy comunes en este tipo de ediciones para la lectura y organización cronológica de las variantes y, excepcionalmente, cuando los símbolos no sean autosuficientes se introducirán algunos comentarios en cursiva.

2) Tomo II: Hacia una recuperación del arquetipo tradicional de Gaiferos libera a Melisenda

Esta es, reconozco, una propuesta editorial arriesgada y menos ortodoxa. El objetivo será, partiendo del itinerario cronológico de los testimonios genéticos, establecido en el volumen anterior (el más antiguo es, en regla general, el menos retocado) llegar a una propuesta de arquetipo que reúna los versos tradicionales oídos o copiados por Garrett para la elaboración de esta versión. No se llegará, sin embargo, a la delimitación de versiones concretas (sabemos, gracias a su testimonio, que contaba con más de una versión). Los eslabones para alcanzar la constitutio textus son los siguientes:

1) collatio y examinatio: cotejo de los testimonios de Garrett de Dom Gaifeiros con las 30 versiones tradicionales portuguesas publicadas y el romance castellano antiguo en la edición de Durán, que Garrett afirma tener como fuente; se hará este trabajo partiendo de unidades mínimas (el hemistiquio), lo que supone el cotejo comentado de los trescientos sesenta y ocho octosílabos del romance, según lo ofrece Garrett en 1851. Esta laboriosa etapa es de gran importancia ya que permite comprobar si el hemistiquio tiene un origen tradicional (en el caso de que alguna versión fidedigna de la tradición oral lo refrende en la totalidad o en buena parte) o si resulta de una traducción del romance antiguo. Podrá existir 
una tercera vía: la minerva de Garrett o, finalmente una cuarta, la desconocida versión del Caballero de Oliveira que, según Garrett, tuvo en cuenta en la elaboración de su romance.

2) Comentarios al proceso creativo de Dom Gaiteros.

3) Determinación de las variantes introducidas por Garrett (por exclusión de fuentes, de acuerdo con los resultados del cotejo) que se expurgarán del texto.

4) Selectio de las lecciones más cercanas a la tradición oral: elaboración de una versión tradicional facticia que toma esta designación por ser un texto elaborado a partir de la selección de variantes de Garrett más cercanas al texto tradicional, de acuerdo con la observación hecha en los testimonios de la tradición oral moderna cotejados. Para que mejor se observe la relación entre los versos tradicionales y los versos de Garrett, se edita en cursiva el verso garrettiano fijado y, abajo, el respectivo verso de la tradición oral.

5) Constitutio Textus: última fase del trabajo crítico. Se lleva a cabo una propuesta de establecimiento del texto de la(s) versión(es) consultada(s) por Garrett de Dom Gaifeiros, basada en la selección de variantes presentes en los testimonios de Garrett más cercanos a la tradición, es decir, los hemistiquios comprobadamente menos retocados por este editor. Se intenta dejar claro con este ejercicio cuáles, de entre estas variantes, coinciden literalmente (o casi) con verdaderas lecciones tradicionales. Se presentan, en letra redonda normal, las variantes comunes entre Garrett y la tradición oral moderna portuguesa y, en cursiva, las lecciones singulares de Garrett. En algunos casos, a fin de poder completar sintáctica y semánticamente el verso, se incluyen vocablos de la tradición oral moderna siempre enmarcados entre corchetes.

A continuación presento mi propuesta de constitución del arquetipo del texto tradicional de Gaiferos, que contrasta profundamente con el largo texto reelaborado que Garrett fijó en sus manuscritos y, asimismo, con el publicado en 1851.

\section{Sentado está Dom Gaifeiros / lá em palacio real}

2 Os dados tinha na mão, / que já os ia deitar senão quando vem seu tio, / que lhe entra a pelejar

$4 \quad$ Para isso és, [Dom] Gaifeiros, / para aos dados jogar Tua espôsa lá teem moiros, / não és para a ir buscar

6 Palavras não eram dittas, os dados vão pelo ar A seu tio, Dom Roldão, / começou de lhe falar

8 Sette annos $a$ busquei, sette, / sem a podêr incontrar os quatro por terra firme, / os tres por cima do mar

10 e os sette annos cumpridos / sem na poder achar Ella estava em Salsonha / lá em palácio real.

12 Mercê vos peço, meu tio, / se m'os vos quizeres dar Vossas armas e cavallo / bem me podeis imprestar

14 A minha esposa entre os moiros / eu a quero ir buscar Minhas armas, meus cavalos / eu não te las posso dar 
16 Meu cavallo é bem vezeiro / não o quero mal vezar As vossas armas, meu tio, / que mas não queiras negar

18 A minha espôsa captiva / como a heide ir buscar? Minhas armas e cavallo / ahi estão a teu mandar

20 e também está meu corpo / para te ir accompanhar Só quero ir, meu tio, / só, para melhor a tirar.

22 Chega ás portas de Sansonha / [........................] deu com um christão captivo / que alli andava a trabalhar.

24 Por Deus te peço, captivo, / que te venha a resgatar Dize-me se tens ouvido / n'esta terra anomear /

26 a uma dama christan $/[\ldots \ldots \ldots \ldots \ldots \ldots \ldots \ldots . . . . .$. que a dama que andas buscando / em palacio deve estar

28 Por essa rua direita / que vai ter ao paço real Melisendra viu estar / sentada áquella janela

30 que as outras em redor d'ella / não n'as sentia folgar D'onde és o cavalleiro / de tam lindo passeiar?

$32-O$ cavalleiro é christão / das bandas d'alem do mar. - Se christão sois, cavalleiro, / recado me heisde levar

34 - Esse recado, senhora / Eu mesmo lh'o heide dar; pois Dom Gaifeiros sou eu / que vos venho a buscar.

36 A falla não era ditta / puseram-se a caminhar tirou-a pelo balcão / por não haver mais logar.

38 Em altos gritos o moiro / começava de bradar:

- Accudam á Melisendra, que se vai para alêm-mar

40 Tomou-a pela cinta, / que o corpo ergueu por lh'a dar.

Como síntesis de las potencialidades de este método que aquí presento se señala la posibilidad de confirmar el uso efectivo del Poeta de versiones de la tradición oral moderna transmontana, al contrario de lo que la crítica intuía. Se recuperan, además, lecciones que se transforman en las más antiguas huellas de la tradición oral moderna del romance de Gaiferos.

\section{Obras citadas}

AMORIM, Gomes de: Garrett. Memórias Biographicas, 3 tomos, Lisboa, Na Imprensa Nacional, 1881 (tomo I) y 1884 (tomos II y III).

Bото, Sandra Cristina de Jesus: As Fontes do Romanceiro de Almeida Garrett. Uma Proposta de 'Edição Crítica'. Tese apresentada à Universidade Nova de Lisboa para cumprimento dos requisitos necessários à obtenção do grau de Doutor no Ramo de Línguas, Literaturas e Culturas, Especialidade de Estudos Literários, Lisboa, 2011, pp. 90-189 (disponible en http://hdl.handle.net/10362/7205). 
BRAgA, Teophilo: Garrett e o Romantismo, Historia da Litteratura Portugueza, Porto, Livraria Chaudron, Casa editora sucesores Lello \& Irmão, 1903.

CINTRA, Luís Filipe Lindley: "Notas à margem do Romanceiro de A. Garrett", Boletim Internacional de Bibliografia Luso-Brasileira, VIII, 1967, pp. 105-135.

FERRÉ, Pere: "Oralidad y escritura en el romancero portugués", en José Jesús de Bustos (coord.), Textualización y oralidad, Madrid, Instituto Universitario Menéndez Pidal / Visor Libros, 2003, pp. 127-156.

FERRÉ, Pere: "Etapas en la edición del romancero portugués" en Ramón Santiago, Ana Valenciano y Silvia Iglesias (eds.), Tradiciones discursivas. Edición de textos orales y escritos, Madrid, Editorial Complutense, 2006, pp. 87-100.

FERRÉ, Pere: "Crítica textual e romanceiro. Breves notas" en Isabel Morujão e Zulmira Santos, Literatura Culta e Popular em Portugal e no Brasil. Homenagem a Arnaldo Saraiva, Porto, Centro de Investigação Transdisciplinar em Cultura, Espaço e Memória / Edições Afrontamento, 2011, pp. 285-291.

GARRETT, Almeida: Colecção Futscher Pereira. Manuscritos garrettianos, autógrafos quase na totalidade, relativos ao Romanceiro. Materiais éditos e inéditos, $1839 ?-1854$ ?

GARRETT, Almeida: "Cancioneiro de Romances, xacaras, Soláos / e outros vestigios / Da Antiga poesia nacional / Pela maior parte conservados na tradição / oral dos povos, / E agora primeiramente colligidos / Por / J. B. de Almeida Garrett", [cuaderno manuscrito autógrafo de la Biblioteca Central de la Faculdade de Letras de la Universidade de Coimbra (signatura UCFL -1-2-1-24)].

GARRETT, Almeida: Romanceiro e Cancioneiro Geral, I, Lisboa, Typ. da Soc. Propagadora dos Conhecim. Uteis, 1843 [reeditado con cambios y añadidos: Romanceiro, I, Lisboa, Em Casa da Viuva Bertrand e Filhos, 1853].

GARRETT, Almeida: Romanceiro, II e III, Lisboa, Na Imprensa Nacional, 1851.

GARRETT, Almeida: Romanceiro, I, II y III, Obras Completas, Lisboa, Estampa [1 ${ }^{\mathrm{a}}$ ed. de 1983, com organização, fixação do texto, prefácio e notas de Augusto da Costa Dias, Maria Helena da Costa Dias e Luís Augusto da Costa Dias; $2^{\mathrm{a}}$ ed. de 1988, com organização, fixação de textos, prefácios e notas de $\mathrm{M}^{\mathrm{a}}$ Helena da Costa Dias, Helena Carvalhão Buescu, Luís Augusto da Costa Dias e João Carlos Faria].

MonTEIRO, Ofélia Paiva: A Formação de Almeida Garrett. Experiência e Criação, 2 vols., Coimbra, Centro de Estudos Românicos, 1971.

TAVANI, Giuseppe: "Edição genética e edição crítico-genética: duas metodologias ou duas filosofias?", Leituras, n $^{\circ}$ 5, Outono de 1999, pp. 143-149. 